\title{
De budas y bodhisattvas: Homenaje a Fernando Tola Mendoza*
}

\author{
Lía Rodríguez de la Vega' \\ Universidad Nacional de Lomas de Zamora, Universidad de Palermo (Argentina)
}

Recibido: febrero 9 de 2016 - Revisado: febrero 29 de 2016 - Aceptado: marzo 24 de 2016

Referencia en formato APA: Rodríguez de la Vega, L. (2016). De budas y bodhisattvas: Homenaje a Fernando Tola Mendoza. Rev. Guillermo de Ockham, 14(1), 135-139. doi: http://dx.doi.org/10.21500/22563202.2316

El doctor Fernando Tola Mendoza, hijo de María Rosa Elena Mendoza de Almenara y de Fernando Tola Cires (abogado y diplomático), nació en Lima, Perú, el 20 de octubre de 1915. Hizo sus estudios secundarios en Bélgica (1930-1935), en la sección grecolatina del Athénée SaintGilles de Bruxelles y allí tomaría contacto con un profesor de sánscrito de quien finalmente no pudo recibir clases -recodemos la antesala de la contienda mundial-, lo que lo convertiría en un fabuloso autodidacta de esa lengua.

De regreso en Perú, llevó a cabo sus estudios universitarios en la Universidad Nacional Mayor de San Marcos, Lima, donde obtuvo los títulos de Bachiller (Licenciado) en Humanidades (1939), Doctor en Literatura (1939), Abogado (1944) y Profesor Emérito (1972). Allí mismo fundó el Instituto Superior de Lingüística y Filología con el profesor Ippolito Galante, donde impartió cursos de latín, griego y literaturas griega y orientales (entre 1935 y 1964) y posteriormente, desde 1958, de sánscrito, pali, filosofía de la India, budismo e hinduismo.

Ocupó diversos cargos en la institución a lo largo de su carrera, entre los que se cuentan el de profesor titular de las materias ya mencionadas, fundador y director del Instituto de Lenguas y Culturas Orientales, fundador y director de la colección Clásicos de Oriente, director entre 1940 y 1962 del Instituto de Filología, director de la revista Sphinx desde su creación hasta 1963 y director del Departamento de Publicaciones de la Facultad de Letras de la Universidad Nacional Mayor de San Marcos, Lima, Perú.
En 1936 obtuvo una beca del Gobierno italiano y ya en 1937 publicó Meghadūta. La nube mensajera. Poema lírico de Kälidāsa y en 1938 Ensayo sobre Śakuntalä" (1938a) y una Selección de Bartṛhari (1938c). Entre 1939 y 1940, publicó extractos del Bhagavad-Gītā, en distintos números de la revista Sphinx (1939 a,b,c; 1940a,b) y en 1943, Notas sobre la filosofía de las Upanișads. Tales publicaciones se complementaron con sus publicaciones referentes al mundo griego, como Neera. Comedia de Demetrio Mosco (1938b), y Los anales de Ennius. etc.

En 1955 obtuvo una beca de la Unesco para Grecia (1955) y en 1956 publicó Muṇdaka-Upanișad. En 1962, obtuvo la beca del Gobierno francés (por la cual siguió los cursos de los profesores L. Renou, E. Lacombe, J. Filliozat, Benveniste y Dumézil, en la Sorbonne y el Collège de France) y la beca del Gobierno alemán (por la que visitó las universidades de Bonn y Tübingen) y en 1964 la beca de la Unesco para Holanda y Checoslovaquia y también para la India (por medio de la cual trabajó en el Bhandarkar Oriental Research Institute, de Puna). La obtención de tales becas se complementó con el avance en sus publicaciones sobre India, entre las que se tienen Poesía sánscrita y poesía alejandrina (1963a) y El estudio del Rg Veda en Europa (1963b).

Hacia fines de 1963 partió a la India donde se desempeñaría como Consejero Cultural de la Embajada de Perú en ese país, entre 1964 y 1969, período en el cual trabajó con varios pandits sobre los Tratados gramaticales de Pānini y sobre poesía sánscrita clásica (Kāvya) y en el

El título alude a que la carrera del Bodhisattva, la Iluminación y la condición misma de Buda (buddha/iluminado) a que ello conduce, no son patrimonio exclusivo de nadie, pudiendo ser aspiraciones de todos los seres humanos (Tola y Dragonetti, 1999).

1. Doctora en Relaciones Internacionales (USAL). Estudios postdoctorales en la UFRGS (Porto Alegre, Brasil). Responsable Del Área de Asia y África de UNICOM, Facultad de Ciencias Sociales (UNLZ), investigadora del CICS (UP) y Coordinadora del Grupo de Trabajo sobre India, Comité de Asuntos Asiáticos, C.A.R.I. Virrey Loreto 2650- 9. "B”, Ciudad Autónoma de Buenos Aires. Código Postal: 1426. E-mail: liadelavega@yahoo.com 
que se casaría con su otrora alumna, la argentina Carmen Dragonetti. En 1965, fue delegado del Perú al Congreso Internacional de Historia de las Religiones celebrado en Clermont, California (Estados Unidos) y en 1969 fue invitado a participar en el Simposio Internacional Verdad y no violencia en el humanismo de Gandhi, organizado por la Unesco y llevado a cabo en París. Paralelamente, continuó con sus publicaciones, entre ellas Patañjali y los orígenes del Kärya (1968a), El individuo en la cultura de la India (1968b), Himnos del Rg Veda (1968c), Himnos del Atharva Veda (1969), Amaru, cien poemas de amor, (1971b) versión directa del sánscrito, introducción y notas (1971a) y Gìta Govinda, traducción del sánscrito, introducción y notas.

En 1970, ya asentado en Buenos Aires se desempeñó como profesor titular de sánscrito, introducción a la filosofía hindú y seminarios sobre la filosofía de la india, en la Universidad de Buenos Aires (sección de estudios de filosofía oriental del Departamento de Filosofía, Facultad de Filosofía y Letras). En 1972 fue nombrado profesor emérito de la Universidad Nacional Mayor de San Marcos (Lima, Perú) y en 1973 publicó Damodara Gupta, Los consejos de la Celestina. Introducción, selección y traducción del sánscrito (1973a), Doctrinas secretas de la India, Upanișads. Introducción, selección, traducción directa del sánscrito y notas (1973b) y Los Yogasūtras de Patañjali, traducción directa del sánscrito, Introducción, Notas y Comentario" (en colaboración con Carmen Dragonetti). Continuando con esta serie de producciones, en 1977 , publicó Bhagavad-Gītā. El canto del señor, traducción directa del sánscrito, introducción y notas y en 1979, Yoga y mistica de la India, en colaboración con Carmen Dragonetti.

Entre 1978 y 1983 fue vicepresidente de la Sociedad Argentina de Orientalistas (SADO) y entre 1983 y 1984, su presidente. De igual modo, en 1980, fue vicepresidente de la Asociación Latinoamericana de Sanscritistas (ALAS) y desde 1981 accedió a la categoría de Investigador Superior de la Comisión Nacional de Investigaciones Científicas y Técnicas (Conicet).

Recibió también diversas distinciones, entre ellas la Orden del Sol, en el grado de Gran Oficial (con la que fue condecorado por el gobierno de Perú, en 1984, por sus aportes a la ciencia y la cultura en el Perú y en la Argentina) y las Palmas Magisteriales, en el grado de Amauta (condecorado por el Gobierno de Perú, en 1986, por su contribución a la formación de discípulos tanto en Perú como en Argentina).

\section{La Fundación Instituto de Estudios Budistas}

En 1989, en conjunto con la doctora Dragonetti el creó la Fundación Instituto de Estudios Budistas (FIEB), reconocida por la Comisión Nacional de Investigaciones Científicas y Técnicas, como lugar de trabajo para llevar a cabo investigaciones científicas. En esta institución desarrollan sus trabajos de investigación en carácter de vicepresidente y presidente de esa institución, respectivamente.

La fundación lleva adelante sus actividades académicas con el objetivo de promover, abordar y llevar a cabo estudios e investigaciones sobre el budismo, sobre las culturas en las cuales este ha florecido (Corea, China, India, Japón, Tíbet, Sudeste Asiático, etc.) y sobre los idiomas por él utilizados (chino, japonés, pali, sánscrito, tibetano, etc.). Al mismo tiempo, dispone de la mayor biblioteca especializada de indología en el ámbito de habla hispana, habiéndose desarrollado en ella diversos cursos y seminarios a cargo de los doctores Tola Mendoza y Dragonetti), entre ellos curso de historia del budismo, cursos de idioma sánscrito, seminario de sánscrito budista híbrido, seminario de chino: lectura de textos budistas, seminario de tibetano: lectura de textos budistas, curso de hīnayāna y mahāyāna: identidad y diferencia, curso de budismo e hinduismo, curso de filosofía budista idealista y curso de filosofía budista Nihilista.

En este mismo año, obtuvo la beca de investigación del Institute for Advanced Studies of World Religions, de The State University of New York at Stony Brook como Lawrence Research Foundation Research Fellow (enero a abril de 1989) y la Beca de investigación del International Institute for Buddhist Studies de Tokyo, Japón (abril a octubre de 1989), en el que fue miembro del grupo constituido por el director del instituto para desarrollar trabajos de investigación semántica sobre los idiomas de los textos budistas originales indios y su traducción en otras áreas de Asia. Sería posteriormente nombrado Overseas Research Fellow.

\section{La creación de la Revista de Estudios Budistas}

En 1991, los doctores Tola Mendoza y Dragonetti, junto con el editor Sergio Mondragón, crearon la Revista de Estudios Budistas (REB), la primera de habla hispana en su género. Inaugurada con un acto en el Colegio de México (junio de 1991), produjo trece números entre 1991 y 1997. Editada en México y dirigida y programada por ellos desde Buenos Aires, contó con un comité con- 
sultivo integrado por los más prestigiosos especialistas en budismo del mundo: André Bareau (Colegio de Francia), Luis Óscar Gómez (Universidad de Michigan), Bimal K. Matilal (Universidad de Oxford), Katsumin Mimaki (Universidad de Kioyo), Lambert Schmithausen (Universidad de Hamburgo), Ernst Steinkellner (Universidad de Viena) y AkiraYuyama (Instituto Internacional para Estudios Budistas, Tokio, Japón).

Los sucesivos números dieron cuenta de artículos originales y traducciones de otros relevantes en el marco de los estudios budistas, escritos por autores como Slvayn Lavi, David Seyfortm Ruegg, Roger Jackson, Junjiro Takakusu y Marcel Hofinger. La prestigiosa revista -hoy digitalizada y accesible sin costo alguno a través de la web-sigue siendo una preciada fuente de consulta en idioma español.

Ese mismo ańo, publicó India and Greece from Alexander to Augustus, en el volumen especial sobre estudios indogrecos en memoria del célebre indólogo griego Demetrius Galanos (1760-1833). De igual modo, durante los años de la revista publicó On the Names of Bhikșus and Bodhisattvas in the Lotus Sütra (1995); Indian Philosophy, Buddhist Conception of Reality (1996a), Buddhist Conception of Reality (1996b) y The Conflict of Change in Buddhism: The Hinayanist reaction (1996c), todo en colaboración con Carmen Dragonetti.

En 1995 fue nombrado miembro correspondiente de la Academia Peruana de la Lengua, en 2000 miembro de honor de la Sociedad Científica Argentina, en 2004 Zaike Bukkyo Kokoro no Kenkyujo-Honorary Overseas Research Fellow (Tokyo) y en 2011, miembro honorario de la Sociedad Internacional de Estudios Budistas (IABS).

En 1999, Tola y Dragonetti publicaron El Sütra del Loto Saddharmapuṇdarikasūtra, traducción del sánscrito, la primera directa del original al espańol y la primera traducción a lengua moderna occidental del siglo xx. En 2004, publicaron su On the Myth of the Opposition between Indian Thought and Western Philosophy y en 2009 Filosofia de la India. Del Veda al Vedānta. El sistema Sāmkhya, obra en la que plantean cuatro tesis centrales que constituyen el eje del libro y giran en torno a la existencia de la filosofía en la India: 1. Por lo menos hasta el siglo Xvir India, por un lado y Grecia y Europa por el otro, reflexionaron sobre los mismos temas filosóficos y de la misma manera. 2. En la historia de las filosofías griega y europea se encuentran manifestaciones de irracionalidad tan numerosas como en la historia del pensamiento de la India. 3. En la India existió filosofía. 4. La comparación entre la filosofía india y la occidental debe limitarse hasta el siglo xviı, de acuerdo con la aparición de nuevos factores en Occidente que lo diferencian marcadamente de otras culturas.

Concluyen que hay que terminar con el mito de que en la India solo hubo pensamiento y no filosofía. En 2014 revisaron la relación entre cultura, ideología y poder, en Ideología o filosofia. El nazismo, Erich Frawwallnery Martin Heidegger y dieron cuenta de la ética que los caracterizó a lo largo de sus carreras.

En 2015, en el marco de la celebración en Buenos Aires de la Primera Jornada Internacional sobre India: "India: diversidades, saberes y poder. Perspectivas desde Latinoamérica” coorganizada por distintas instituciones de educación superior argentinas y auspiciada por la Embajada de la India en la República Argentina, recibió el homenaje de sus discípulos y colegas por sus primeros cien años. Para la ocasión pronuncia dos conferencias: El Mahābhārata y La obra monumental de Pāninini, que serían replicadas en el xv Congreso Internacional de la Asociación Latinoamericana de Estudios de Asia y África (Aladaa) "Identidad, pertinencia e impacto de los estudios de Asia y África en América Latina”, llevado a cabo en Chile, con la presencia y el testimonio de sus colegas y amigos Graciela de La Lama, Flora Botton Beja y Luis Gómez.

Por su parte, 2016 lo encuentra junto a la doctora Dragonetti finalizando la traducción del sánscrito al español del Vimalakīrtinirdeśasūtra, cuyo texto sánscrito ha sido recientemente descubierto por un grupo de investigadores japoneses. Finalizaba también la revisión de una traducción del pali al español de siete sūtra del canon pali de la secta theravada (Jâliyasutta, Potthapadasutta, Mahasihanadasutta, Kevattasutta, Subhasutta, Lohichchasutta y Tevijjasutta), con la idea de publicar el texto en Taiwán hacia fin de año a través de Dharma Publishing Organization, que a había publicado la segunda edición revisada y aumentada del Sūtra del Loto, también en español. De igual modo, esperan también la impresión de una nueva edición aumentada y corregida de una selección de Upanișads hecha por ambos, al tiempo que el doctor Tola supervisa la digitalización de la biblioteca de Fieb, llevada a cabo por un grupo de colaboradores de la institución taiwanesa Dharma Drum, con la que FIEB tiene convenio.

Su espíritu incansable abarcó el estudio de idiomas como el sánscrito, sánscrito budista híbrido, pali, chino, tibetano y japonés. De igual modo, habla francés, inglés, alemán, portugués, italiano, español, hindi, griego, latín y persa antiguo.

$\mathrm{Su}$ impresionante trayectoria profesional solo y asociado a su compañera de vida Carmen Dragonetti, ha 
permitido el aporte de preciadas contribuciones a los campos de estudio abordados a través de las numerosas publicaciones producidas de las que solo podemos brindar un mínimo panorama. Entre ellas está su permanente trabajo para enfrentar exitosamente el prejuicio de la no existencia de filosofía en la India; su labor con los Yogasūtras de Patañjali, que señaló nuevas direcciones de estudio; su investigación sobre anāditva en las diversas formas de manifestación del pensamiento de la India que posibilitó la comprensión de temáticas no consideradas anteriormente bajo esa nueva perspectiva, y su traducción del Sūtra del Loto, del sánscrito budista híbrido al español, entre muchas otras (véase Rodríguez de la Vega y Vofchuk, 2010). De igual modo, resulta crucial a su trabajo la constitución del espańol como lengua de conocimiento en este campo de estudios, así como su difusión en otros diversos idiomas de su producción académica en él, y el despliegue a lo largo de su carrera de una ética ejemplar que adelantó discusiones sobre el diálogo intercultural que formó a distintas generaciones de alumnos y discípulos y hacen de sus cien años de intensa y fecunda vida, un muy preciado bien/virtud para todos los que de una u otra manera hemos tenido el privilegio de ser tocados por sus influencias. Bien valen para él las palabras del Dhammapada, en su capítulo sobre la Felicidad:

Como la luna se acoge a sus constelaciones,

Acogeos al sabio,

Inteligente y culto,

Paciente, que cumple sus deberes,

Noble, bueno y sagaz

[Con humildad y enorme orgullo de ustedes, así hacemos, maestro].

\section{Referencias}

Dragonetti, C. y Tola, F. (2004). Dhammapada. La esencia de la sabiduría budista. New Jersey: Primordia.

Rodríguez de la Vega, L. y Vofchuck, R. (2010). Los estudios sobre la India en la República Argentina. Homenaje a Fernando Tola y Carmen Dragonetti. Publicación realizada en ocasión del Congreso Nacional de ALADAA: "Asia y África en Argentina. Caminos hacia una sociedad intercultural" (20 y 21 de agosto de 2010. Escuela de Estudios Orientales, Universidad del Salvador). Auspiciado por ALADAA, Sección Argentina; cátedra de Demografía Social, Departamento de Derecho y Ciencia Política, UNLaM y cátedra de Sánscrito, Facultad de Filosofía y Letras, UBA.
Tola, F. (1937). Meghadūta. La nube mensajera. Poema lirico de Kālidāsa. Rev. Sphinx, 1 (1), 61-94.

Tola, F. (1938a). Ensayo sobre Śakuntalā. Lima: Instituto de Filología, Universidad Nacional Mayor de San Marcos.

Tola, F. (1938b).Neera Comedia de Demetrio Mosco. Texto griego. Traducción, introducción ynotas. Rev. Sphinx, ll (3), $9-45$.

Tola, F. (1938c). Selección de Bartrihari. Lima: Instituto de Filología, Universidad Nacional Mayor de San Marcos.

Tola, F. (1939a). Bhagavad-Gītā. Rev.Sphinx, lll (4-5), 39-51.

Tola, F. (1939b). Bhagavad-Gītā. Rev.Sphinx, lll (6-7), 93-105.

Tola, F. (1939c). Bhagavad-Gìtā. Rev. Sphinx, 8, 75-85.

Tola, F. (1939d). Los Anales de Ennius. Rev. Sphinx, lll (8), $9-23$.

Tola, F. (1940a). Bhagavad-Gītā. Rev. Sphinx, IV (9), 39-47.

Tola, F. (1940b). Bhagavad-Gītā. Rev. Sphinx,IV (10, 11, 12), 37-49.

Tola, F. (1943). Notas sobre la filosofía de las Upaniṣads. Revista Letras, IV.

Tola, F. (1956). Mundaka-Upanișad. Lima: Instituto de Filología, Universidad Nacional Mayor de San Marcos.

Tola, F. (1963a). Poesía sánscrita y poesía alejandrina. Rev. Sphinx, 15.

Tola, F. (1963b). El estudio del Rg Veda en Europa. Lima: Instituto de Lenguas y Culturas Orientales, Universidad Nacional Mayor de San Marcos.

Tola, F. (1968a). Patañjali y los orígenes del Kāvya. Rev. Estudios Orientales,lll (1), 66-84.

Tola, F. (1968b). El individuo en la cultura de la India. Rev. San Marcos, X.

Tola, F. (1968c). Himnos del Rg Veda. Buenos Aires: Sudamericana.

Tola, F. (1969). Himnos del Atharva Veda. Buenos Aires: Sudamericana.

Tola, F. (1971a). Amaru, cien poemas de amor, versión directa del sánscrito, Introducción y notas. Barcelona: Barral Editores.

Tola, F. (1971b). Gìta Govinda, traducción del sánscrito. Introducción y notas. Buenos Aires: Sudamericana.

Tola, F. (1973a). Damodara Gupta. Los consejos de La Celestina. Introducción, selección y traducción del sánscrito. Barcelona: Barral Editores.

Tola, F. (1973b). Doctrinas secretas de la india. Upanișads. Introducción, selección, traducción directa del sánscrito y notas. Barcelona: Barral Editores. 
Tola, F. (1977). Bhagavad-Gītā. El canto del señor. Traducción directa del sánscrito, introducción y notas. Caracas-Buenos Aires: Monte Ávila Ediciones.

Tola, F., \& Dragonetti, C. (1973). Los Yogasūtras de Patañjali. Traducción directa del sánscrito, introducción, notas y comentarios. Barcelona: Barral Editores.

Tola, F., \& Dragonetti, C. (1979). Yoga y mística de la India. Buenos Aires: Kier.

Tola, F., \& Dragonetti, C. (1991). India and Greece from Alexander to Augustus. En: Volumen especial sobre estudios Indo-grecos en memoria del célebre indólogo griego Demetrius Galanos (1760-1833), Indo-Greek cultural Society-RohilkhandUniversity, Graeco-Indica-India's Cultural Contacts with the Greek World, Bareilly, India.

Tola, F., \& Dragonetti, C. (1995b). On the Names of Bhikșus and Bodhisattvas in the Lotus Sūtra. Hokke Bunka Kenkyu.

Tola, F., \& Dragonetti, C. (1996a). Indian Philosophy. En Felicitation. Volume in honour of Professor R.M. Sharma New Delhi, India.
Tola, F., \& Dragonetti, C. (1996b). Buddhist Conception of Reality. Journal of the Indian Council of Philosophica IResearch, 14 (1), 35-64.

Tola, F., \& Dragonetti, C. (1996c). The Conflict of Change in Buddhism: The Hīnayānist Reaction. Cahiers d'Extrême Asie, Kyoto, 9 (1), 233-254.

Tola, F., \& Dragonetti, C. (1999). El Sūtra del Loto: Saddharmapundarīkasūtra, traducción del Sánscrito, Introducciones, Notas e Indices. México: El Colegio de México.

Tola, F., \& Dragonetti, C. (2004). On the Myth of the Opposition between Indian Thought and Western Philosophy. Hildesheim: Georg OLMS Verlag.

Tola, F., \& Dragonetti, C. (2008). Filosofía de la India. (Del Veda al Vedānta. El sistema Sāmkhya). El mito de la oposición entre "pensamiento" indio y "filosofía" occidental. Barcelona: Kairós.

Tola, F., \& Dragonetti, C. (2014). Ideología o filosofía. El nazismo, Erich Frauwallner y Martin Heidegger. Buenos Aires: Las Cuarenta. 